\title{
PROBLEMATIKA PERLINDUNGAN HUKUM TERHADAP PARA PIHAK DALAM TRANSAKSI LAYANAN URUNAN DANA MELALUI PENAWARAN SAHAM BERBASIS TEKNOLOGI INFORMASI (EQUITY-BASED CROWDFUNDING)
}

\author{
Viodi Childnadi Widodo \\ E-mail: viodywidodo20@gmail.com \\ Mahasiswa Fakultas Hukum Universitas Sebelas Maret Surakarta \\ Dona Budi Kharisma \\ E-mail: donabudikharisma@staff.uns.ac.id \\ Dosen Fakultas Hukum Universitas Sebelas Maret Surakarta
}

\begin{abstract}
The purpose aims to find out the form of legal protection to the parties and the problematic that facing by Financial Services Authority to provide effort of legal protection for the parties in the service of equity crowdfunding. This legal research is a descriptive empirical law research. The research location is Financial Services Authority Surakarta. The research types and source of data include primary and secondary data with using by a qualitative analysis technique. The results of this research explain the problematic that facing by Financial Services Authority to provide effort of legal protection in the service of equity crowdfunding which is divided into three factors that is : (a) legal substance, (b) legal structure, and (c) legal culture.
\end{abstract}

Keywords: Legal Protection; Problematic; Equity Crowdfunding

\begin{abstract}
Abstrak
Penulisan ini bertujuan untuk mengetahui bentuk perlindungan hukum kepada para pihak serta problematika yang dihadapi oleh Otoritas Jasa Keuangan dalam memberikan upaya perlindungan hukum kepada para pihak dalam layanan equity crowdfunding. Penelitian ini merupakan penelitian hukum empiris yang bersifat deskriptif kualitatif. Lokasi penelitian dilakukan di Otoritas Jasa Keuangan Surakarta. Jenis dan sumber data penelitian ini meliputi data primer dan data sekunder dengan menggunakan teknik analisis kualitatif. Hasil penelitian ini menjelaskan problematika dalam memberikan upaya perlindungan hukum pada para pihak yang dihadapi oleh Otoritas Jasa Keuangan dalam layanan equity crowdfunding yang terbagi menjadi tiga faktor yaitu: (a) substansi hukum, (b) struktur hukum, dan (c) budaya hukum.
\end{abstract}

Kata Kunci: Perlindungan Hukum; Problematika; Equity Crowdfunding

\section{A. Pendahuluan}

Perkembangan Ekonomi digital menimbulkan inovasi-inovasi baru di bidang keuangan. Inovasi baru jasa pelayanan keuangan yang memanfaatkan kecanggihan teknologi populer dengan istilah financial technology (fintech). Financial technology (fintech) pada hakekatnya merupakan teknologi yang menjadi penghubung antara sektor finansial dengan pengguna atau masyarakat umum. Inovasi yang ditawarkan Fintech sangat luas dan dalam berbagai segmen, baik itu B2B (Business to Business) hingga B2C (Business to Consumer). Fintech berpotensi untuk mempengaruhi kebiasaan transaksi masyarakat menjadi lebih praktis dan efektif. Hal yang menyebabkan fintech berpotensi mempengaruhi pertumbuhan ekonomi di Indonesia. Menurut kajian Institute for Development of Economics and Finance (Indef) bersama dengan Asosiasi Fintech Indonesia (Aftech), dampak Industri teknologi finansial (Fintech) terhadap perekonomian Indonesia mencapai Rp25,97 triliun. 
Berdasarkan klasifikasi menurut Bank Indonesia (BI) salah satu jenis fintech yang tengah berkembang adalah crowdfunding. Crowdfunding merupakan inovasi baru dalam dunia keuangan. Crowdfunding merupakan skema intermediasi keuangan berbasis internet yang mengumpulkan dana dari masyarakat umum atau disebut dengan crowd (kerumunan). Dalam perkembangannya, Crowdfunding tidak hanya sebagai lembaga intermediasi keuangan saja melainkan berperan dalam membentuk rule of social capital. Salah satu teknologi finansial (fintech) di bidang crowdfunding yang tengah berkembang saat ini adalah equity crowdfunding. Perusahaan fintech equity crowdfunding menawarkan aplikasi yang bisa mempertemukan pemilik dan dengan startup atau UKM yang membutuhkan suntikan dana. Hal ini tentu membuka kesempatan bagi pelaku usaha startup atau UKM untuk mendapatkan pendanaan guna menjalankan bisnisnya.

Equity Crowdfunding merupakan hal yang relatif baru di Indonesia. Hal tersebut tentunya tidak menghalangi equity crowdfunding dapat menjadi alternatif pendanaan yang bisa digunakan perusahaan startup dan UMKM yang ingin memperluas segmen usahanya. Biasanya, bisnis startup apalagi dalam skala kecil akan mengalami kesulitan dalam masalah meminjam modal di Bank. Rendahnya presentasi kredibilitas peminjam dan rendahnya kemungkinan untuk mengembalikan, serta tidak adanya jaminan aset yang bisa digunakan seandainya peminjam mengalami gagal bayar. Dengan adanya suatu gebrakan baru seperti equity crowdfunding akan membuka peluang pendanaan untuk bisnis startup dan UMKM (Usaha Mikro Kecil Menengah) menjadi lebih mudah. Selain itu, pendanaan melalui equity crowdfunding biasanya memiliki biaya yang lebih rendah daripada jika meminjam di bank. Begitu pula bagi para penyandang dana, berinvestasi melalui equity crowdfunding memberikan return lebih tinggi dari deposito di bank, meskipun dengan risiko yang lebih tinggi pula.

OJK (Otoritas Jasa Keuangan) selaku regulator industri keuangan di Indonesia, sudah mengatur tentang layanan urun dana melalui POJK Nomor 37/POJK.04/2018 tentang Layanan Urun Dana Melalui Penawaran Saham Berbasis Teknologi Informasi (Equity Crowdfunding). Di dalam peraturan tersebut sudah diatur mengenai beberapa hal tentang layanan urun dana salah satunya adalah kepastian dan perlindungan hukum terhadap Pemodal dan Penerbit. Dengan adanya kepastian hukum dan perlindungan bagi para pihak, diharapkan dapat memberikan ruang bertumbuh bagi perusahaan perintis (startup company) untuk memperoleh akses pendanaan di Pasar Modal serta meningkatkan inklusi sektor keuangan di Indonesia, dan juga menjamin bagi para pemodal dan penerbit bahwa hak-hak dan kewajibannya dilindungi oleh hukum.

Berdasarkan fakta-fakta tersebut ditengarai bahwa meskipun belum banyak kasus mengenai equity crowdfunding, akan tetapi alangkah baiknya mencegah resiko-resiko yang akan timbul dengan memperjelas ketentuan peraturan baru mengenai equity crowdfunding. Maka dari itu artikel ini membahas mengenai problematika perlindungan hukum kepada para pihak dalam kegiatan equity crowdfunding berdasarkan tiga faktor yaitu substansi hukum, struktur hukum dan budaya hukum.

\section{B. Metode Penelitian}

Merujuk pada judul dan pendahuluan, maka jenis penelitian yang digunakan penulis adalah penelitian hukum empiris. Dalam hal ini sifat empirisme ditunjukan dengan data-data yang terkait dengan perlindungan hukum yang diberikan oleh Otoritas Jasa Keuangan terhadap para pihak dalam kegiatan equity crowdfunding. Pada penelitian hukum sosiologis atau empiris, maka yang diteliti pada awalnya adalah data sekunder, kemudian dilanjutkan dengan penelitian terhadap data primer di lapangan, atau terhadap masyarakat (Soerjono Soekanto, 2014:10). Penulisan hukum ini bersifat deskriptif yaitu penelitian yang memberikan data seteliti mungkin mengenai manusia, keadaan, atau gejala-gejala lainnya (Soerjono Soekanto, 2014 :10) Dalam penelitian ini, penulis menggunakan pendekatan Kualitatif. Peneliti menekankan catatan yang menggambarkan situasi sebenarnya guna mendukung penyajian data (HB Sutopo, 2006: 35). 


\section{Hasil Penelitian dan Pembahasan}

Untuk mengkaji problematika hukum peneliti menggunakan teori sistem hukum Lawrence M. Friedman. Friedman menyatakan bahwa hukum dapat efektif dan berhasil apabila didukung oleh tiga unsur system hukum, yakni struktur hukum (struktur of law), substansi hukum (substance of the law) dan budaya hukum (legal culture) (Lawrence M. Friedman, 1975:16). Tiga unsur dari sistem hukum menurut Lawrence $\mathrm{M}$. Friedman tersebut di atas merupakan jiwa atau ruh yang menggerakkan hukum sebagai suatu sistem sosial yang memiliki karakter dan teknik khusus dalam pengkajiannya. Selanjutnya untuk mengkaji problematika yang dihadapi oleh Otoritas Jasa Keuangan dalam memberikan upaya perlindungan hukum kepada para Pihak dalam equity crowdfunding Peneliti mengkaji sebagai berikut:

1. Problematika Legal Substance atau Substansi Hukum dalam Memberikan Upaya Perlindungan Hukum Kepada Para Pihak

Berdasarkan teori Lawrence M. Friedman, yang dimaksud dengan legal substance atau substansi hukum adalah aturan, norma, dan pola perilaku nyata manusia yang berada dalam sistem itu. Jadi substansi hukum menyangkut peraturan perundang-undangan yang berlaku yang memiliki kekuatan yang mengikat dan menjadi pedoman bagi aparat penegak hukum. Legal substance atau yang biasa disebut substansi hukum merupakan unsur penting yang menentukan bisa atau tidaknya hukum itu dilaksanakan.

Berdasarkan dari hasil penelitian yang Penulis lakukan di Otoritas Jasa Keuangan Surakarta, didapatkan bahwa ada beberapa problematika substansial yang dihadapi oleh OJK dalam memberikan upaya perlindungan hukum kepada para pihak dalam kegiatan equity crowdfunding. Hasil penelitian menunjukkan belum optimalnya Peraturan Otoritas Jasa Keuangan Nomor 37/POJK.04/2018 tentang Layanan Urun Dana Melalui Penawaran Saham Berbasis Teknologi Informasi (Equity Crowdfunding) dalam mengatur mengenai hak dan kewajiban para pihak dalam kegiatan tersebut agar tercapai perlindungan hukum bagi para pihak.

Hasil penelitian menjelaskan, masih ada peraturan yang kurang mendetail dalam menjelaskan mengenai kepastian dan perlindungan hukum kepada para pihak dalam kegiatan equity crowdfunding berdasarkan Undang-Undang Nomor 8 Tahun 1995 tentang Pasar Modal.

Undang-Undang Nomor 8 Tahun 1995 tentang Pasar Modal dan dipertegas kembali pada Undang-Undang Nomor 21 Tahun 2011 tentang Otoritas Jasa Keuangan menjelaskan batasan mengenai pengertian pasar modal yaitu kegiatan yang berkaitan dengan penawaran umum dan perdagangan efek, perusahaan publik yang berkaitan dengan efek yang diterbitkannya, serta Lembaga dan Profesi yang berkaitan dengan efek. Dapat dikatakan bahwa UU Pasar Modal dalam memberi arti kepada pasar modal tidak memberi suatu definisi secara menyeluruh melainkan menitikberatkan kepada kegiatan dan para pelaku dari suatu pasar modal.

Berdasarkan pengertian pasar modal dalam UU Pasar Modal, maka kegiatan yang dimaksud yang berkaitan dengan:

1) Penawaran Umum

Berdasarkan Pasal 1 angka 15 Undang-Undang Pasar Modal, penawaran umum didefinisikan sebagai kegiatan penawaran Efek yang dilakukan oleh Emiten untuk menjual Efek kepada masyarakat. Emiten adalah Pihak yang melakukan Penawaran Umum, di mana Emiten wajib menyampaikan pernyataan pendaftaran kepada otoritas pasar modal untuk melakukan penawaran umum.

2) Perdagangan Efek

Berdasarkan Penjelasan Pasal 90 Undang-Undang Pasar Modal, kegiatan perdagangan efek adalah kegiatan yang meliputi kegiatan penawaran, pembelian, dan atau penjualan Efek yang terjadi dalam rangka Penawaran Umum, atau terjadi di Bursa Efek, maupun kegiatan penawaran, pembelian dan atau penjualan Efek di luar Bursa Efek atas Efek Emiten atau Perusahaan Publik. 
3) Perusahaan Publik

Berdasarkan Pasal 1 Angka 22 Undang-Undang Pasar Modal, Perusahaan Publik adalah Perseroan yang sahamnya telah dimiliki sekurang-kurangnya oleh 300 pemegang saham dan memiliki modal disetor sekurang-kurangnya Rp3.000.000.000,- atau suatu jumlah pemegang saham dan modal disetor yang ditetapkan dengan Peraturan Pemerintah.

4) Lembaga Profesi yang berkaitan dengan Efek

Berdasarkan Pasal 1 Angka 9 Undang-Undang Pasar Modal, Lembaga yang berkaitan dengan efek adalah Lembaga Penunjang Pasar Modal, Lembaga Kliring dan Penjaminan.

Berdasarkan ketentuan di atas, dapat disimpulkan bahwa Undang-Undang Pasar Modal hanya memberikan pengertian yang sempit dari pasar modal. Menurut ketentuan di atas, fokus utama dari dalam Undang-Undang Pasar Modal hanya mengenai Penawaran Umum. Apabila dilihat kembali pengertian pasar modal menurut Munir Fuady, pasar modal adalah suatu tempat atau sistem dipenuhinya kebutuhan-kebutuhan dana untuk kapital suatu perusahaan, merupakan pasar tempat orang membeli dan menjual surat efek yang baru dikeluarkan(Munir Fuady, 1996:10). Mengacu pengertian di atas, tempat dilakukannya perdagangan efek seharusnya tidak bisa hanya mengacu kepada kegiatan penawaran umum, sebagaimana yang diatur dalam Undang-Undang Pasar Modal (Naomi Norita dan Deborah Harahap, 2019:10).

Menurut Pasal 6 Undang-Undang Nomor 21 Tahun 2011 tentang Otoritas Jasa Keuangan menyatakan bahwa pengaturan dan pengawasan oleh OJK salah satunya adalah dalam kegiatan jasa keuangan di sektor pasar modal. Definisi pasar modal berdasarkan UndnagUndang OJK juga diatur secara sempit dan mengacu pada ketentuan dalam Undang-Undang Pasar Modal. Namun, berdasarkan ketentuan Pasal 4 POJK Nomor 37/POJK.04/2018 kegiatan equity crowdfunding dikategorikan sebagai kegiatan sektor jasa keuangan di sektor pasar modal. Hal tersebut tentunya menimbulkan ketidakjelasan yang terkait pengaturan mengenai equity crowdfunding, yang seharusnya tidak masuk dalam definisi pasar modal menurut Undang-Undang Pasar Modal dan Undang-Undang OJK, namun dimasukkan sebagai kegiatan jasa keuangan di sektor pasar modal.

Berdasarkan ketentuan diatas maka equity crowdfunding mempunyai keterkaitan dengan perdagangan efek dalam hal ini adalah saham Penerbit. Equity crowdfunding mempunyai sistem yang mempertemukan antara Penerbit dengan Pemodal. Dalam hal ini Pihak penyelenggara menyediakan platform di mana Penerbit saham dapat mengumpulkan dana dari Pemodal untuk memperluas atau mengembangkan bisnis mereka. Sedangkan Pemodal menerima saham sebagai timbal balik atas modal yang diinvestasikannya. Mekanisme timbal balik tersebut diatur di dalam Undang-Undang Pasar Modal.

Lebih lanjut, equity crowdfunding memberikan konsep baru kegiatan penawaran saham dan menurut ketentuan yang ada merupakan bagian dari pasar modal. Sehingga pada hakikatnya kegiatan equity crowdfunding termasuk pasar modal. Pada intinya equity crowdfunding mempunyai hubungan dengan perusahaan efek dalam hal saham Penerbit. OJK sebagai lembaga pengaturan juga mengkategorikan equity crowdfunding sebagai kegiatan jasa keuangan dalam sektor pasar modal dalam POJK Nomor 37/POJK.04/2018.

Namun, sangat disayangkan dan menjadi pertanyaan apabila definisi pasar modal berdasarkan Undang-Undang Pasar Modal sebagaimana ditegaskan lebih lanjut dalam Undang-Undang OJK, yang seharusnya menjadi acuan POJK Nomor 37/POJK.04/2018 kurang detail dan hanya mencakup bagian mengenai kegiatan penawaran umum dan perdagangan efek sebagaimana yang diatur dalam Undang-Undang Pasar Modal. Menurut Peneliti, alangkah lebih baiknya ketentuan-ketentuan dalam Undang-Undang Pasar Modal mengenai konsep seharusnya menyesuaikan dengan berkembangan zaman khususnya perkembangan financial technology. Hal tersebut guna menjamin kepastian dan perlindungan hukum kepada para pihak. 
2. Problematika Legal Structure OJK dalam Memberikan Upaya Perlindungan Hukum pada Kegiatan Equity Crowdfunding

Dalam teori Lawrence M. Friedman legal structure atau yang biasa disebut dengan struktur hukum merupakan unsur penting yang menentukan bisa atau tidaknya hukum itu dilaksanakan dengan baik. Hukum tidak dapat berjalan atau tegak bila tidak ada aparat penegak hukum yang kredibilitas, kompeten dan independen. Jadi, legal structure terdiri dari lembaga hukum yang ada dimaksudkan untuk menjalankan perangkat hukum yang ada.

Berdasarkan dari hasil penelitian yang Penulis lakukan, didapatkan bahwa ada beberapa problematika struktural yang dihadapi oleh OJK dalam memberikan upaya perlindungan hukum kepada para pihak dalam kegiatan equity crowdfunding. Hasil penelitian menunjukkan struktur-struktur hukum tersebut kurang optimal dalam penerapan untuk memberikan kepastian perlindungan hukum kepada para pihak, antara lain:

a. Tidak adanya ketentuan mengenai mitigasi risiko dalam platform Equity Crowdfunding

Equity crowdfunding bisa dikatakan merupakan suatu alternatif permodalan yang relatif baru dan berkembang di Indonesia. Dalam penerapannya, equity crowdfunding dikelola oleh Penyelenggara dengan diawasi oleh OJK sebagai regulator. Penyelenggara equity crowdfunding berbentuk perseroan terbatas maupun koperasi yang menyediakan, mengelola, dan mengoperasikan layanan equity crowdfunding bagi para pihak khususnya Penerbit dan Pemodal. Dalam mekanismenya, Penyelenggara menyediakan platform sebagai sarana dan prasarana untuk menunjang kegiatan equity crowdfunding, juga sebagai penghubung antara Pemodal dengan Penerbit.

Berdasarkan Pasal 46 hingga Pasal 47 POJK Nomor 37/POJK.04/2018 tentang Layanan Urun Dana Melalui Penawaran Saham Berbasis Teknologi Informasi, Mitigasi Risiko merupakan hal yang wajib diterapkan oleh Penyelenggara. Dalam penerapannya, ada problematika dalam hal platform Penyelenggara dimana platform-platform tersebut kurang menjelaskan mitigasi risiko dalam kegiatan equity crowdfunding. Potensi-potensi risiko yang terjadi dalam kegiatan tersebut adalah Pemodal yang kehilangan modalnya, perencanaan bisnis yang tidak sesuai dengan rencana awal, saham tidak likuid, ataupun kegagalan operasional Penyelenggara. Hal tersebut yang menimbulkan terhambatnya upaya untuk memberikan perlindungan terhadap para pihak.

Di dalam sistem tersebut, kurang menyediakan kejelasan mitigasi risiko apabila terdapat risiko yang merugikan Pemodal ataupun Penerbit. Seharusnya Penyelenggara menyediakan informasi mengenai antar para pihak agar bisa mengetahui informasi antara satu sama lain, akan tetapi untuk sekarang ini masih ada beberapa Penyelenggara yang tidak menyediakan informasi mengenai informasi mitigasi risiko. Hal tersebut dapat menyebabkan kerugian terhadap para pihak khususnya Pemodal. Hal ini menjadi sistem platform tersebut masih kurang penjelasan bagi perlindungan hukum khususnya Pemodal. Tidakny ada penjelasan lebih lanjut mengenai penerapan mitigasi risiko dalam rangka memberikan perlindungan hukum secara preventif dapat membuat Pemodal kehilangan kepercayaan kepada layanan equity crowdfunding.

3. Problematika Legal Culture yang Dihadapi OJK dalam Memberikan Upaya Perlindungan Hukum pada Kegiatan Equity Crowdfunding

Berdasarkan penelitian yang Penulis lakukan, edukasi dan sosialiasi terhadap masyarakat belum mampu menjangkau seluruh lapisan masyarakat, dari segi literasi keuangan maupun iklusi keuangan. Hal tersebut masih banyak masyarakat yang kurang peduli akan pentingnya informasi akan hal tersebut. Berdasarkan fenomena yang Peneliti analisa, penyebabnya adalah kebiasaan masyarakat yang cenderung menganggap equity crowdfunding sebagai metode investasi konvensional. Kepercayaan masyarakat terhadap investasi dan sistem online yang rendah serta budaya yang konsumtif menyebabkan rendahnya tingkat investasi di Indonesia. 
Hal tersebut kadang yang menimbulkan investasi asal-asalan tanpa mempertimbangkan perlindungan hukum terhadap Pengguna.

Menurut Penulis, equity crowdfunding sebenarnya sudah mulai berjalan di Indonesia namun belum begitu dikenal oleh masyarakat. Dalam rangka untuk meningkatkan pemahaman masyarakat mengenai equity crowdfunding beserta hak-hak dan kewajiban sebagai pengguna, wajib bagi Penyelenggara dan perlu support pemerintah dalam hal ini OJK untuk memberikan minimal pengetahuan dasar berinvestasi agar para investor pemula tersebut tidak gegabah yang dapat menyebabkan mereka dirugikan secara hukum. Hal ini sekaligus juga sebagai sosialisasi untuk mengenalkan skema crowdfunding kepada masyarakat luas agar masyarakat mengetahui manfaat dan risiko yang timbul dalam equity crowdfunding.

\section{Simpulan}

Berdasarkan penjelasan hasil penelitian dan pembahasan, perlindungan hukum dalam kegiatan equity crowdfunding belum optimal, hal tersebut disebabkan adanya problematika yang dihadapi OJK dalam memberikan upaya perlindungan hukum kepada para pihak dalam bentuk (a) substansi hukum yang berupa kurang detailnya berdasarkan Undang-Undang Pasar Modal sebagaimana ditegaskan lebih lanjut dalam Undang-Undang Otoritas Jasa Keuangan, yang seharusnya menjadi acuan POJK Nomor 37/POJK.04/2018 kurang detail dan hanya mencakup bagian mengenai kegiatan penawaran umum dan perdagangan efek sebagaimana yang diatur dalam Undang-Undang Pasar Modal, (b) struktur hukum yang berupa platform Penyelenggara kurang menyediakan kejelasan mitigasi risiko apabila terdapat risiko yang merugikan Pemodal ataupun Penerbit, dan (c) budaya hukum yang berupa masyarakat yang kurang peduli akan pentingnya informasi mengenai bentuk perlindungan hukum terhadap Pengguna.

\section{E. Saran}

Otoritas Jasa Keuangan seharusnya menerapkan ketentuan-ketentuan baru dalam UndangUndang Pasar Modal mengenai konsep untuk mengikuti perkembangan zaman khususnya perkembangan financial technology. Hal tersebut guna menjamin kepastian dan perlindungan hukum kepada para pihak. Penjelasan lebih lanjut mengenai kewajiban kepada Penyelenggara mengenai penerapan mitigasi risiko dalam rangka memberikan perlindungan hukum secara preventif. Seharusnya, Penyelenggara perlu support pemerintah dalam hal ini OJK untuk memberikan minimal pengetahuan dasar berinvestasi agar para investor pemula tersebut tidak gegabah yang dapat menyebabkan mereka dirugikan secara hukum.

\section{F. Daftar Pustaka}

\section{Buku}

Freedman, David M. Dan Matthew R. Nutting. 2015. Equity Crowdfunding for Investors : A Guide to Risks, Returns, Regulations, Funding Portals, Due Diligence, and Deal Terms. New Jersey : John Wiley \& Sons Inc.

Hariyani, Iswi dan R. Serfianto Dibyo Purnomo. 2010. Buku Pintar Hukum Bisnis Pasar Modal: Strategi Tepat Investasi Saham, Obligasi, Waran, Right, Opsi, Reksadana, dan Produk Pasar Modal Syariah. Cet.1. Jakarta: Visimedia.

H.B Sutopo. 2006. Metodologi Penelitain Kualitatif Dasar Teori dan Terapannya dalam Penelitian. Surakarta: UNS Press.

Soerjono Soekanto. 2010. Pengantar Penelitian Hukum. Jakarta: Universitas Indonesia. 
Jurnal

Agrawal A., Catalini C., dan A. Goldfarb. "Some Simple Economics of Crowdfunding" . NBER Working Paper. Michigan: University of Michigan.

Akerlof, A George. 1970. "The Market for Lemons: Quality Uncertainty and the Market Mechanism.” . The Quarterly Journal of Economics 84. Bekerley : University of California.

Belleflamme, P., Lambert, T., \& Schwienbacher, A. 2013. "Crowdfunding: Tapping The Right Crowd". Journal of Business Venturing. Pennyslavnia : The Wharton School of the University Of Pennyslvania.

Brüntje, D. and Gajda, O. 2015. "Crowdfunding in Europe: State of the Art in Theory and Practice". Journal of Business Law. Heidelberg : University of Heidelberg.

Budhijanto, Danrivanto. 2011. "Pembentukan Hukum Yang Antisipatif Terhadap Perkembangan Zaman Dalam Dimensi Konvergensi Teknologi Informasi dan Komunikasi“ . Jurnal IImu Hukum 2. Bandung : Fakultas Hukum. Universitas Padjajaran.

Gita Widi Bhawika. 2017. "Risiko Dehumanisasi pada Crowdfunding sebagai Akses Pendanaan Berbasis Teknologi di Indonesia". Jurnal Sosial dan Humaniora. Volume 10. Edisi 1. Surabaya. Fakultas Bisnis dan Manajemen Teknologi. Institut Teknologi Sepuluh November.

Jonker Sihombing. 2012. "Analisis Hukum Otoritas Jasa Keuangan dan Pengawasan Pasar Modal". Jurnal Hukum Bisnis, Volume 31 No.1 Tahun 2012.

Matteo Rossi. 2014. "The New Ways to Raise Capital: An Exploratory Study of Crowdfunding". Volume 5. Number 2. International Journal of Financial Research. Benevento : DEMM Department, University of Sannio.

Salahuddin Rijal Arifin dan Wisudanto. 2017. "Crowdfunding sebagai Alternatif Pembiayaan Pembangungan Infrastruktur". Jurnal Hukum Bisnis. Palembang : University Network for Indonesia Infrastructure Development.

Schwartz, Andrew. 2013. "Crowdfunding Securities. "Notre Dame Law Review 88, Boston : Notre Dame University (Juni, 2013): 1457-90.

Wandi Adiansah, Nandang Mulyana dan Muhammad Fedryansyah. 2016. "Potensi Crowdfunding di Indonesia dalam Praktik Pekerjaan Sosial". Jurnal Bisnis. Bandung : Fakultas Ekonomi. Universitas Padjajaran.

\section{Internet}

www.academia.edu/28733057/Startup_sebagai_Digitalisasi_Ekonomi_dan_Dampaknya_bagi_ Ekonomi_Kreatif_di_Indonesia diakses pada 26 Februari 19.35

https://konsumen.ojk.go.id/MinisiteDPLK/ diakses pada 1 Juli 201919.17

http://respository.usu.ac.id/bitstream/123456789/35732/6/chapter\%20III-V.pdf diakses pada 1 Juli 2019 20.32

\section{Perundang-Undangan}

Kitab Undang-Undang Hukum Perdata

Undang-Undang Nomor 8 Tahun 1995 tentang Pasar Modal

Peraturan Otoritas Jasa Keuangan Nomor 13/POJK.02/2018 tentang Inovasi Keuangan Digital di Sektor Jasa Keuangan

Peraturan Otoritas Jasa Keuangan Nomor 37/POJK.04/2018 tentang Layanan Urun Dana Melalui Penawaran Saham Berbasis Teknologi Informasi (Equity Crowdfunding) 